\title{
Orbital Anastomoses of the Anterior Deep Temporal Artery
}

\author{
R.G. Quisling* and J.F. Seeger \\ Department of Radiology, University of Michigan Medical Center, Ann Arbor, Michigan, U.S.A. \\ Received: September 13, 1974
}

\begin{abstract}
Summary. The anterior deep temporal artery may provide a major collateral pathway to the intracranial circulation through anastomoses with branches of the ophthalmic artery. Review of carotid angiograms in 26 patients with internal carotid artery occlusive disease revealed anterior deep temporal to ophthalmic artery anastomoses in 16 cases. This route of collateral blood flow was associated in most instances with total occlusion of the cervical portion of the internal carotid artery. Three cases demonstrating the angiographic anatomy of the anterior deep temporal artery and its potential anastomoses with branches of the ophthalmic artery are presented.
\end{abstract}

Anastomoses orbitaires de l'artère temporale profonde antérieure

Résumé. L'artère temporale profonde antérieure peut être à l'origine de circulation colatérale grâce à ses ana- stomoses avec l'artère ophtalmique. Une telle anastomose a été constatée 16 fois sur 26 cas de thrombose de l'artère carotide interne.

\section{Anastomosen der A. temporalis ant. zur Orbita}

Zusammenfassung. Über die A. temporalis anterior ist über Anastomosen zu den Ästen der A. ophthalmica ein Kollateral-Kreislauf zu den intracraniellen Gefäßab. schnitten möglich. Bei 26 Patienten mit einem A. carotis interna-Verschluß zeigte sich dieser Kreislauf in 16 Fällen. Es wird über 3 Fälle ausführlich berichtet, bei denen die angiographische Anatomie der A. temporalis anterior und die möglichen Anastomosen mit Ästen der A. ophthalmica besprochen wird.
Anatomical and angiographic descriptions of anastomoses between branches of the internalmaxillary artery and the ophthalmic artery or internal carotid artery have been reported previously $[2,4,5,6,7,9$, 10, 11, 12]. Although illustrated by Hawkins [5] and Lie [7] the arteriographic features of the anterior deep temporal artery (ADTA) to ophthalmic artery anastomoses have never been defined precisely. The present report describes and illustrates the angiographic anatomy of the ADTA and its connection with the lacrimal and supraorbital branches of the ophthalmic artery and emphasizes the role of such collaterals in cerebrovascular occlusive disease.

\section{Anatomy}

The anterior deep temporal artery is a branch of the second portion of the internal maxillary artery. From its origin in the infratemporal fossa near the lateral pterygoid plate it courses in an anterior and superior direction. According to Gray, a branch of the ADTA communicates with the lacrimal artery after passing into the orbit through the zygomaticotemporal foramen [3]. An additional anastomosis is mentioned between the ADTA and a branch of the lacrimal artery after passing through an unnamed foramen in the

* During this investigation, R.G. Quisling was a NINDS Special Fellow F11NS57-73. greater wing of the sphenoid bone [3]. The main trunk of the ADTA continues superiorly to supply the temporal muscle. Distal branches of the ADTA anastomose with peripheral branches of the superficial temporal and supraorbital arteries $[4,8]$.

\section{Material and Methods}

The carotid angiograms of twenty-six patients with either marked stenosis or occlusion of the cervical portion of the internal carotid artery were reviewed. Twenty-five of these patients were studied because of transient cerebral ischemic attacks and one to evaluate a previous entrapment procedure for a right cavernous carotid artery aneurysm. In 16 of the 26 cases, collateral pathways were visualized between the ADTA and branches of the ophthalmic artery. Two of these cases are presented. A third case demonstrating this anastomosis with otherwise normal cerebral angiography is also reported.

\section{Case Reports}

Case 1. E. R., a 45 year old female with mild hypertension, was shown, two years previously, to have fibromuscular dysplasia of both renal arteries. She presented on this admission with cerebral ischemic 
symptoms referable to the right cerebral hemisphere. Complete cerebral angiography revealed mild fibromuscular disease of the cervical portion of the left internal carotid artery and total occlusion of the cervical portion of the right internal carotid artery.

The right carotid angiogram demonstrates the usual angiographic appearance of the ADTA to lacrimal artery anastomasis (Fig. 1a,b). A branch of the ADTA penetrates the zygomaticotemporal foramen and anastomoses with the lacrimal artery near the anterolateral orbital rim. The lacrimal artery fills in a retrograde manner to join the main ophthalmic artery. Distal branches of the ADTA anastomose with superficial lacrimal artery following a typical course as described in Case 1. This anastomosis provides the only angiographic evidence of collateral circulation to the right ophthalmic artery. The posterior division of the ADTA courses superiorly and joins distal branches of the superficial temporal artery.

Case 3. M.S., a 25 year old female, presented with migraine headaches, anisocoria and a sluggish left pupillary response. No abnormalities were demonstrated by complete cerebral angiography.

Right common carotid angiography reveal two separate anastomoses between the ADTA and the ophthalmic artery (Fig. 3). The usual ADTA to lacri-
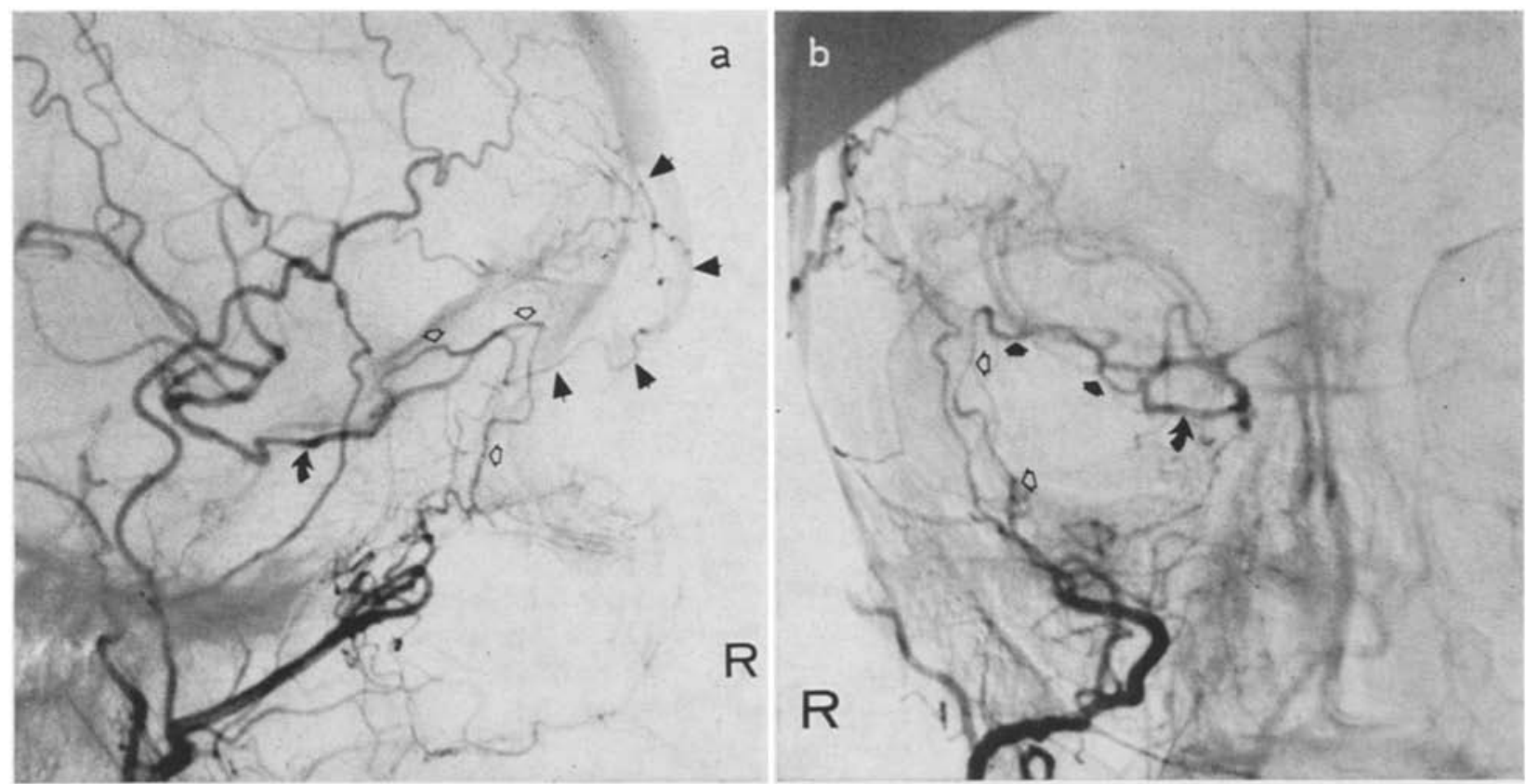

Fig. 1. Case 1: a) right common carotid injection. Lateral projection demonstrates ADTA (lower open arrow) to lacrimal artery (upper open arrows) anastomosis, with retrograde filling of main ophthalmic artery (curved arrow). Note also superficial temporal to ophthalmic artery anastomoses (solid arrows); b) frontal projection demonstrates ADTA (open arrows) to lacrimal artery (solid arrows) anastomosis and retrograde opacification of ophthalmic artery (curved arrow)

temporal artery branches which subsequently anastomose with the supraorbital artery to provide additional collateral circulation.

Case 2. A.D., a 24 year old female, had undergone an entrapment procedure for a previously demonstrated right cavernous carotid aneurysm. The ophthalmic artery had been ligated at its origin. Complete cerebral angiography demonstrated successful entrapment of the aneurysm, with excellent collateral circulation to the right hemisphere through the anterior and right posterior communicating arteries.

The right carotid angiogram (Fig. 2) shows apparent bifurcation of the ADTA into an anterior and a posterior division. The anterior branch anastomoses with the mal artery anastomosis, as demonstrated in Cases 1 and 2, courses along the superolateral aspect of the orbit. A second, less commonly seen collateral channel, passes along the inferolateral aspect of the orbit and presumably connects the ADTA with a prominent inferior muscular branch of the lacrimal artery.

\section{Discussion}

Three potential routes of collateral flow are available between the ADTA and branches of the ophthalmic artery. The most important and most frequently seen is a communication between the ADTA and the 
lacrimal branch of the ophthalmic artery, which was present in 16 of our 26 cases. When this anastomotic vessel is prominent, either congenitally or, more commonly, when it serves as a collateral in occlusive vascular disease, it becomes a major branch of the ADTA. In such situations, the ADTA angiographically appears to bifurcate (Fig. 2). The anterior division is that branch which anastomoses with the lacrimal artery, while the posterior division, the usual continuation of the ADTA, supplies the temporal muscle and anastomoses with peripheral branches of the superficial temporal artery. This latter anastomosis may then provide a second route of collateral circulation to the orbit

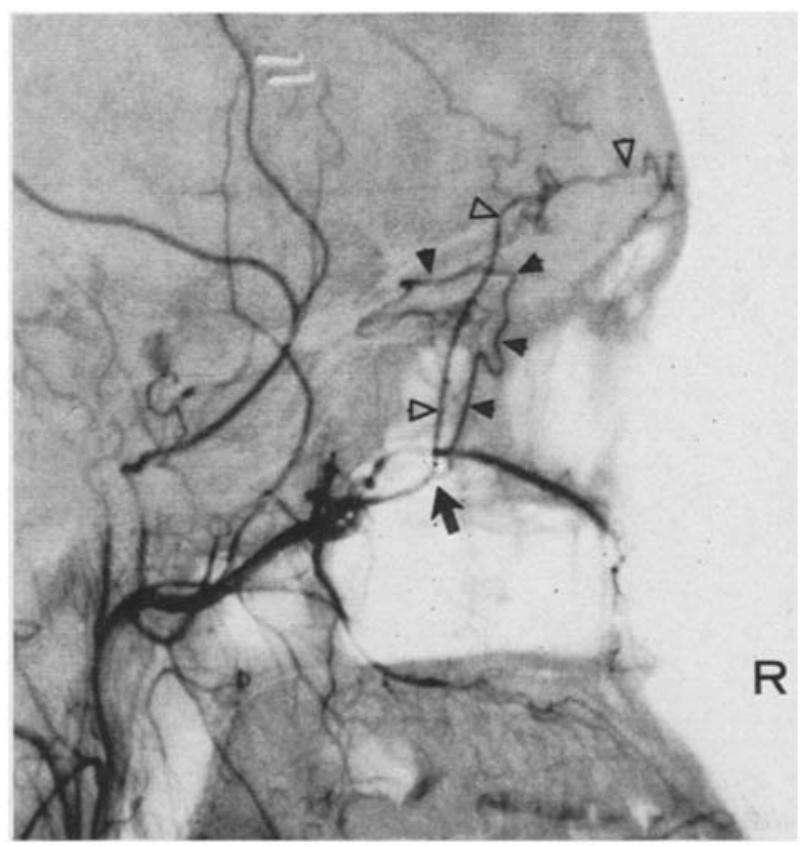

Fig. 2. Case 2: right common carotid injection. Lateral projection demonstrates bifurcation of ADTA (large solid arrow). The anterior branch anastomoses with lacrimal artery (solid arrowheads). The posterior branch anastomoses with superficial temporal artery branches (open arrowheads)

through connections with the supraorbital branch of the ophthalmic artery (Fig. 1).

A third pathway between the anterior division of the ADTA and a branch of the lacrimal artery differs from the first in that it penetrates the skull through the greater wing of the sphenoid and passes along the inferolateral aspect of the orbit rather than following the usual course along the superolateral aspect (Fig. 3). This pathway was seen in two of our cases.

The ADTA to ophthalmic artery communications are most frequently demonstrated angiographically in patients with complete occlusion of the ipsilateral internal carotid artery, and less commonly with high grade stenosis of the internal carotid artery. In such situations, the ophthalmic artery usually serves as a collateral to the internal carotid circulation. These anastomoses may, as in four of our 26 cases of carotid occlusive disease, provide the only angiographically visible blood supply to the ophthalmic artery. Oc-

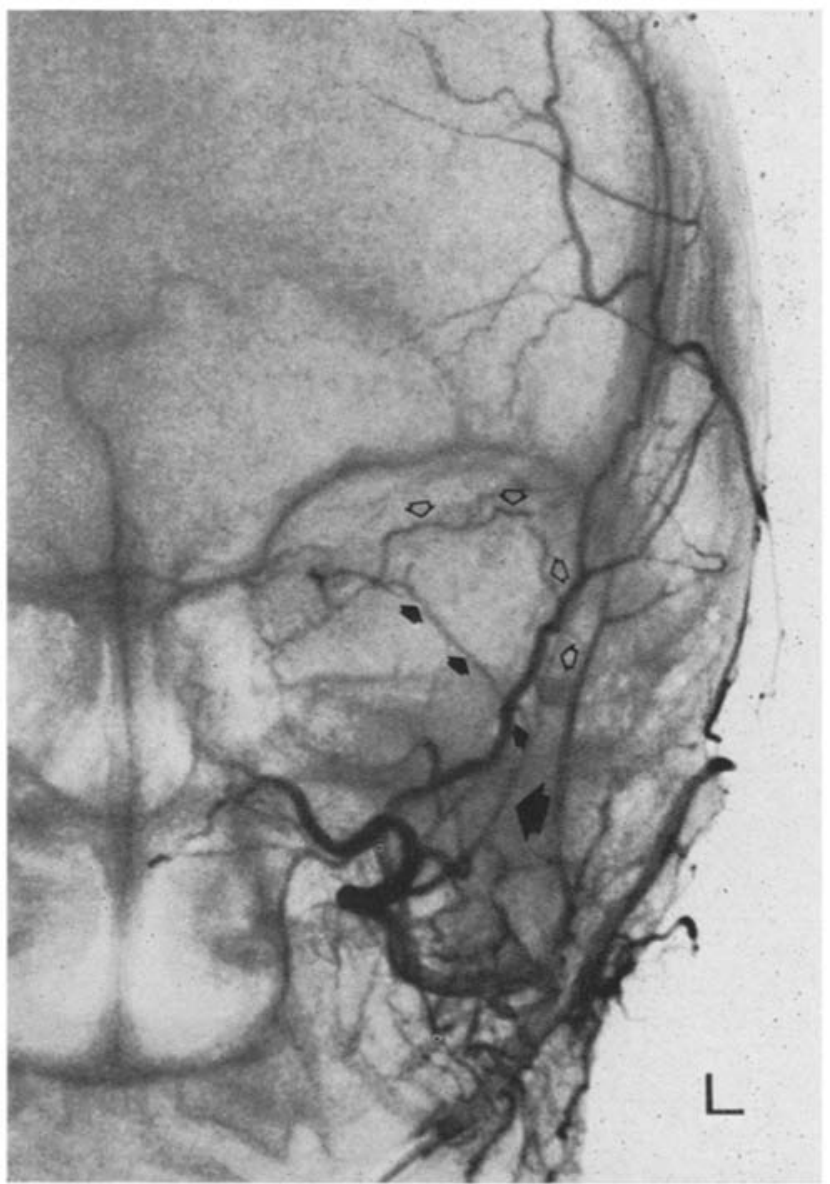

Fig. 3. Case 3: left common carotid injection. AP projection demonstrates usual anastomosis (open arrows) between ADTA (large solid arrow) and lacrimal artery. Note additional anastomosis (closed arrows) with lacrimal ar. tery

easionally, vascular tumors or vascular malformations supplied by branches of the ophthalmic artery may also cause enlargement of the AD'TA to ophthalmic anastomoses. Finally, one should be aware that these anastomoses may at times be found in patients with no known vascular abnormalities (Case 3), presumably representing a normal developmental variation.

\section{References}

1. Allen III, W.E., Kier, E.L., Rothman, S.L.G.: The maxillary artery: Normal arteriographic anatomy. Amer. J. Roentgenol. 118, 517-527 (1973)

2. Doyon, D., Markovits, P., Aaron, C., Simon, J., Richard, J., Gasquet, V., Paugam, B.: Etudé radio- 
anatomique de la carotide externe. J. Radiol. Electrol. 48, 301-307 (1966)

3. Gray, H.: Anatomy of the human body, twentyeighth edition. Edited by C.M. Goss. Philadelphia: Lea and Febiger 1967

4. Hayreh, S. S.: The ophthalmic artery III. Branches. Brit. J. Ophthal. 46, 212-247 (1962)

5. Hawkins, T.D.: The collateral anastomosis in cerebrovascular occlusion. Clin. Radiol. 17, 203-219 (1966)

6. Koo, A.M., Newton, T.H.: Pseudoxanthoma elasticum associated with carotid rete mirabile. Amer. J. Roentgenol. 116, 16-22 (1971)

7. Lie, T.A.: Congenital anomalies of the carotid arteries. Amsterdam: Exerpta Medica Foundation 1968

8. Lurje, A.: On the topographical anatomy of the internal maxillary artery. Acta. Anat. 2, 219-231 (1946)

9. Margolis, M.T., Newton, T.H.: Collateral pathways between the cavernous portion of the internal carotid and external carotid arteries. Radiology 93, 834-836 (1969)

10. Newton, T.H., Hoyt, W.F.: Dural arteriovenous shunts in the region of the cavernous sinus. Neuroradiol. 1, 71-81 (1970)

11. Padget, D. H. : The development of the cranial arteries in the human embryo. Contr. Embryol. Carneg. Instn. 32, 205-261 (1948)

12. Vignaud, J., Hasso, A.N., Lasjaunias, P., Clay, C.: Orbital vascular anatomy and embryology. Radiology 111, $617-626(1974)$

Joachim F. Seeger, M.D.

Department of Radiology

Neuroradiology Section,

University of Michigan Medical Center

Ann Arbor, Mich. 48104

U.S.A. 